\title{
Odontology prize 2020
}

(c) The Society of The Nippon Dental University 2020

Sufyan Garoushi, Pekka Vallittu, Akikazu Shinya and Lippo Lassila were awarded the ODONTOLOGY PRIZE 2020 for the best science paper in recognition of outstanding originality and significance in the paper.

"Influence of increment thickness on light transmission, degree of conversion and micro hardness of bulk fill composites".
Odontology, volume 104, number 3, page 291-297, 2016.

Publisher's Note Springer Nature remains neutral with regard to jurisdictional claims in published maps and institutional affiliations. 